\title{
The Role of Oxidative Stress in Modulation of the Relaxant Responses of Saphenous Vein and Internal Mammary Artery
}

\author{
Andrew Duncan Muir ${ }^{1}$, Pascal Patrick McKeown ${ }^{1}$ and Ulvi Bayraktutan*,1,2 \\ ${ }^{I}$ Department of Medicine, Institute of Clinical Science, Queen's University Belfast, Belfast and ${ }^{2}$ Division of Stroke \\ Medicine, Clinical Sciences Building, University of Nottingham, Nottingham, UK
}

\begin{abstract}
Altered endothelial activity is enumerated amongst the leading causes of graft dysfunction following coronary artery bypass surgery and may account for differences in patency between arterial and venous grafts. This study investigates whether differences exist between basal endothelial functions of saphenous vein (SV) and internal mammary arteries (IMA) and explores the putative involvements of reactive oxygen species in this phenomenon. Basal relaxations were greater in IMA than SV. Specific inhibitor of nitric oxide synthase (L-NAME) attenuated dilatory responses while a superoxide anion scavenger (Tiron) displayed a positive effect in both vessel types. MnTBAP, a superoxide dismutase mimetic, improved relaxation in the SV only whereas specific inhibitors of pro-oxidant enzyme NADPH oxidase and cGMP pathway reduced that of the IMA. Rotenone, allopurinol and indomethacin diminished relaxations in the IMA but accentuated SV dilatation. In conclusion, the greater intrinsic antioxidant capacity may explain why IMA make better conduits than SV.
\end{abstract}

Keywords: Endothelial dysfunction, coronary artery bypass grafting, internal mammary artery, saphenous vein, reactive oxygen species.

\section{INTRODUCTION}

Human internal mammary arteries (IMA), despite their exposure to the same intrathoracic pressure and circulating risk factors as coronary arteries, do not generally develop macroscopic atherosclerotic plaques and therefore make the best conduits for coronary artery bypass grafting (CABG). Saphenous veins (SV) are also routinely used as conduits despite their considerably reduced patency rates compared to arterial grafts $[1,2]$. Although the underlying mechanisms contributing to different patency rates between arterial and venous grafts remain largely unknown, altered endothelial function in these vessels has been implicated as a contributing factor [3-6].

Endothelium generates many substances including nitric oxide (NO) to maintain normal vascular function [7]. However, its characteristics change in pathological conditions leading to a phenomenon called "endothelial dysfunction", which is characterised by impaired endothelium-dependent relaxation [7]. In large arteries, NO is largely generated by endothelial NO synthase (eNOS) and constitutes the most potent endothelium-derived vasodilatory agent. Uncoupling of eNOS due to reduced availability of its cofactor tetrahydrobiopterin and overproduction of reactive oxygen species (ROS) especially superoxide anion $\left(\mathrm{O}_{2}^{-{ }^{-}}\right)$by pro-oxidant enzyme NADPH oxidase may contribute to the pathogenesis of endothelial dysfunction and graft failure

*Address correspondence to this author at the Division of Stroke Medicine, Clinical Sciences Building, University of Nottingham, Hucknall Road, Nottingham NG5 1PB, United Kingdom; Tel: +44 115 8231764;

Fax: +44 115 8231767; E-mail: ulvi.bayraktutan@nottingham.ac.uk
$[5,8] . \mathrm{O}_{2}{ }^{-}$is known to be the foundation molecule of all ROS [9]. It regulates vascular tone directly by scavenging $\mathrm{NO}$ and indirectly by producing peroxynitrite $\left(\mathrm{OONO}^{-}\right)$in the process and reducing intracellular levels of antioxidant glutathione and cysteine. Other enzymes, including cyclooxygenase, xanthine oxidase and mitochondrial NADH dehydrogenase, can also produce $\mathrm{O}_{2}{ }^{-}$in the vasculature [10]. Under normal conditions $\mathrm{CuZn}-$ or Mn-containing superoxide dismutases (SOD) metabolise $\mathrm{O}_{2}{ }^{-}$into hydrogen peroxide $\left(\mathrm{H}_{2} \mathrm{O}_{2}\right)$, which in turn is catabolised to $\mathrm{H}_{2} \mathrm{O}$ by antioxidant enzymes catalase and glutathione peroxidase (GPx) [11].

Given the nature of this metabolic cascade, it is reasonable to hypothesise that the delicate balance between local levels of ROS and the intrinsic antioxidant capacity of vessels to neutralise them may render arterial conduits superior to their venous counterparts. The current study investigated this hypothesis using IMA and SV segments and comparing their endothelial responses via isometric tension studies. It also investigated the roles of endotheliumdependent hyperpolarising factor (EDHF) and cyclic guanylyl monophosphate (cGMP) pathway in putative functional differences. These two conduits were chosen as they remain the commonest chosen for CABG.

\section{MATERIALS AND METHODOLOGY}

\section{Patients}

Patients undergoing non-emergency CABG were recruited for this study. No specific inclusion or exclusion criteria were applied to the patient population except that the surgical procedure was carried out during the normal working day. This study had the approval of the local Research Ethics Committee (Queen's University of Belfast) 
and all patients gave written informed consent. Vascular samples were harvested from the operating theatres prior to pressure testing of each vessel to avoid distension injury. Samples were immersed in $50 \mathrm{~mL}$ of Krebs buffer solution ([in $\mathrm{mM}$ ]: $\mathrm{NaCl} 118.3, \mathrm{KCl} 4.7, \mathrm{MgSO}_{4} 1.2, \mathrm{KH}_{2} \mathrm{PO}_{4} 1.22$, $\mathrm{CaCl}_{2} 2.5, \mathrm{NaHCO}_{3} 25$, glucose 11.1; $\left.\mathrm{pH} 7.4\right]$ and carried to the laboratory in an icebox. All experiments were commenced within 1 hour of harvest.

\section{Vasoactivity}

Vascular samples were dissected free of their surrounding tissues and divided into 2-3 $\mathrm{mm}$ rings. Following calibration of the data acquisition system, the rings were mounted between triangular stirrups and placed in $25 \mathrm{ml}$ organ baths filled with carbonated $\left(95 \% \mathrm{O}_{2} / 5 \% \mathrm{CO}_{2}\right)$ Krebs buffer. Data were captured through force transducers via an 8-channel data acquisition system (ML780) and recorded in Chart v4 (ADInstruments Ltd., UK). After mounting, the vascular rings were allowed to equilibrate for $90 \mathrm{~min}$ under $2.5 \mathrm{~g}$ and $1.5 \mathrm{~g}$ tension for IMA and SV segments, respectively.

The experiments were started by obtaining a doseresponse curve to phenylephrine (PE; 0.001 to $30 \mu \mathrm{M}$ ). Rings were then washed and equilibrated prior to contraction with submaximal concentration of $\mathrm{PE}$ before detecting endothelium-dependent relaxant responses to acetylcholine (ACh; 0.001 to $30 \mu \mathrm{M}$ ). The rings were washed again and pre-incubated for $20 \mathrm{~min}$ with one of the study chemicals prior to detection of the ACh-mediated relaxant responses. This procedure allowed each vessel to act as its own control. Segments were randomly assigned to each of the study chemicals. Following another washout, the abovementioned process was repeated with sodium nitroprusside (SNP; 0.001 to $3 \mu \mathrm{M}$ ) to investigate endothelium-independent relaxant responses. Finally, the vascular rings were washed and subjected to a single concentration of potassium $(120 \mathrm{mM})$ to stimulate the smooth muscle. The rings were air-dried overnight then weighed to index their contractions.

\section{Study Chemicals}

Comparisons were made between vascular rings prior to and following incubation with substances known to regulate the synthesis or local levels of various ROS. L-NAME $\left(10^{-}\right.$ $\left.{ }^{4} \mathrm{M}\right)$ and ebselen $\left(4 \times 10^{-5} \mathrm{M}\right)$ were used to suppress the availabilities of $\mathrm{NO}$ and $\mathrm{H}_{2} \mathrm{O}_{2}$, respectively. MnTBAP, a SOD mimetic $\left(10^{-5} \mathrm{M}\right)$, Tiron (10-6 and 10-5) and a range of specific enzyme inhibitors $\left(10^{-6}\right.$ and $\left.10^{-5} \mathrm{M}\right)$, namely rotenone (mitochondrial complex I, $10^{-5} \mathrm{M}$ ), allopurinol (xanthine oxidase, $10^{-5} \mathrm{M}$ ) and indomethacin (cyclooxygenase, $10^{-5} \mathrm{M}$ ) were used to reduce the quantity of $\mathrm{O}_{2}{ }^{--}$. The specific contribution of NADPH oxidase on vasoactivity was assessed using a series of functionally distinct inhibitors, namely phenylarsine oxide (PAO, $\left.10^{-5} \mathrm{M}\right)$, diphenyleneiodonium (DPI, $\left.3 \times 10^{-7} \mathrm{M}\right)$ and (4-(2aminoethyl)benzenesulfonyl fluoride (AEBSF, $10^{-5} \mathrm{M}$ ). ODQ (1h-[1, 2, 4]oxadiazolo[4,3-a]quinoxalin-1-one, $3 \times 10^{-7}$ and $10^{-5} \mathrm{M}$ ) was used to study the effect of cGMP second messenger pathway in NO mediated vasodilatations. All chemicals were sourced from Sigma-Aldrich (Sigma-Aldrich Company Ltd., Gillingham, England) except for MnTBAP which was supplied by AG Scientific (AG Scientific Incorporated, San Diego, USA).

\section{Statistical Analysis}

Data are expressed as mean \pm SEM. Dose-response curves were fitted by non-linear regression with simplex algorithm. Relaxant responses were given as the percentages of PE precontraction. Analyses of relaxant responses were undertaken using repeated measures two-way ANOVA with individual chemical comparisons being paired. Statistical analysis of the contractile responses was performed by Student's t-test for paired observations. $\mathrm{P}<0.05$ was considered statistically significant. Multiple vessel segments from individual patients within a group were averaged prior to analysis when appropriate..

\section{RESULTS}

A total of 490 vascular rings from 126 patients were studied. Patients' characteristics are shown in Table $\mathbf{1}$.

\section{Table 1. Patient Characteristics}

\begin{tabular}{|c|c|}
\hline Characteristics & Patients \\
\hline Age & $29-82$ years (median 67 years) \\
\hline Gender & 103 \\
\hline \multicolumn{2}{|l|}{ Male } \\
\hline Female & 23 \\
\hline Vascular Risk Factors & 24 \\
\hline \multicolumn{2}{|l|}{ Current Smoker } \\
\hline Ex-Smoker & 62 \\
\hline Non-Smoker & 40 \\
\hline Diabetic & 33 \\
\hline Non-diabetic & 93 \\
\hline Hypertensive & 67 \\
\hline Non-hypertensive & 59 \\
\hline Drug Therapy & 125 \\
\hline Anti-Platelet & \\
\hline Statin & 119 \\
\hline Beta-Blocker & 107 \\
\hline ACE-Inhibitor & 95 \\
\hline Calcium Channel Blocker & 29 \\
\hline Potassium Channel Activator & 61 \\
\hline Nitrate & 62 \\
\hline Diuretic & 38 \\
\hline
\end{tabular}

\section{Basal Relaxant and Contractile Responses}

Both endothelium-dependent and endotheliumindependent dilatations were greater in IMA than SV (Fig. 1A-B). Contractions evoked by high potassium solution (120 

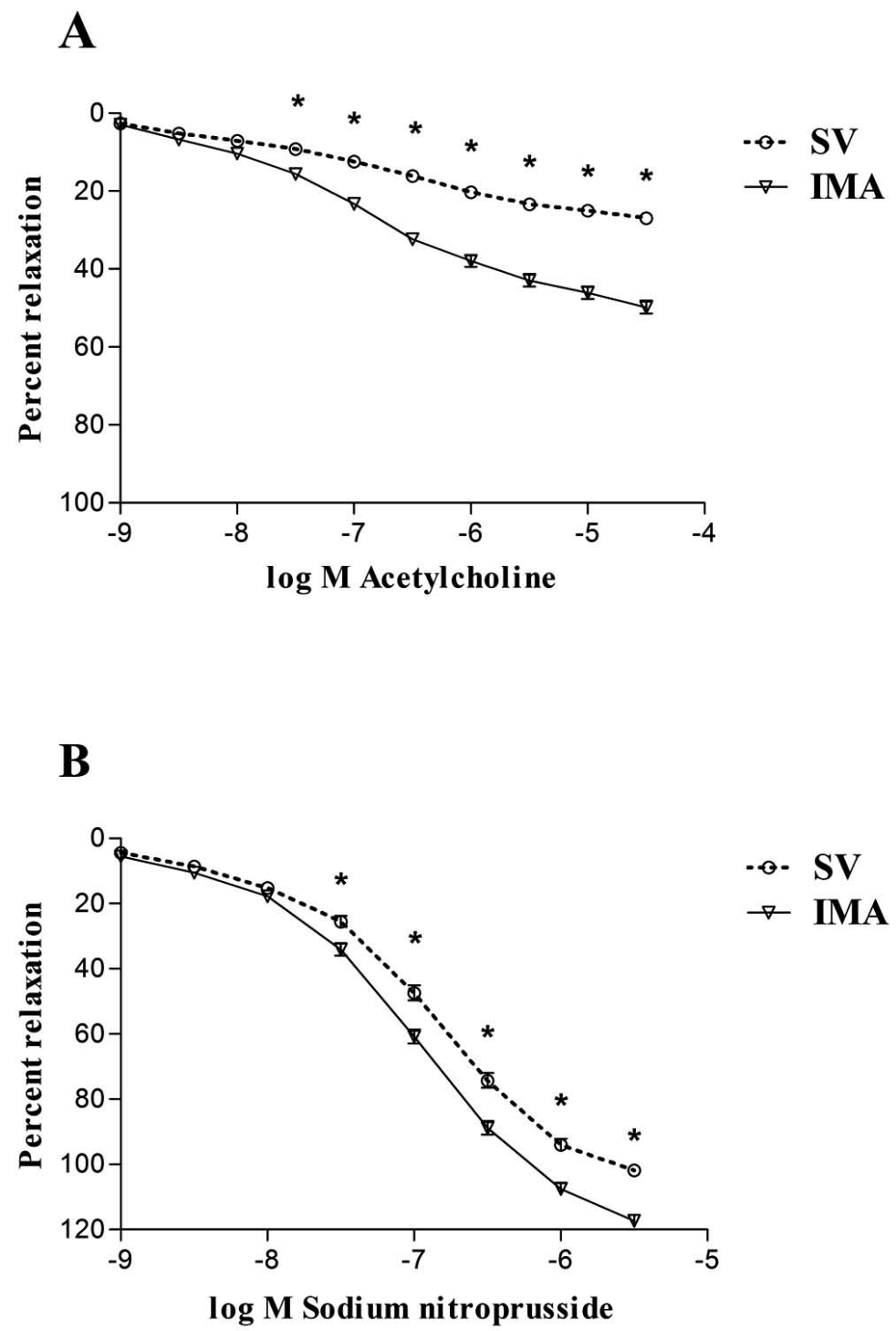

Fig. (1). Endothelium-dependent (A) and independent (B) relaxant responses in IMA and SV. Results are expressed as mean \pm SEM from 20 different patients. ${ }^{*} \mathrm{p}<0.05$ compared to the other conduit.

$\mathrm{mM}$ ) were also significantly greater in IMA than SV $(938.3 \pm 42.4$ vs. $724.7 \pm 38.7$ g per gram dry tissue, $p<0.001)$.

\section{Impact of ROS on Endothelium-Dependent Vasorelaxations}

The reductions of $\mathrm{NO}$ and $\mathrm{H}_{2} \mathrm{O}_{2}$ levels by L-NAME and ebselen, respectively resulted in attenuation and preservation of relaxant responses in both IMA and SV. The decrease in $\mathrm{O}_{2}{ }^{--}$by MnTBAP produced selective improvements in $\mathrm{SV}$ relaxant responses without affecting those of IMA (Fig. 2AC). Tiron $\left(10^{-5}\right.$ and $\left.10^{-6} \mathrm{M}\right)$ slightly but insignificantly improved vasodilatation in both conduits regardless of its concentrations (Fig. 2D showing responses to $10^{-5} \mathrm{M}$ Tiron).

Manipulation of $\mathrm{O}_{2}^{--}$levels by a variety of NADPH oxidase inhibitors with additional properties revealed different responses in that incubation of vascular rings with a neutrophil oxidase inhibitor (PAO) improved relaxant responses in both arterial and venous segments while inhibitors of flavoproteins and serine proteases (DPI and
AEBSF, respectively) attenuated these responses in IMA segments and failed to alter those of SV (Fig. 3A-C).

The inhibitors of other enzymes that affect $\mathrm{O}_{2}^{--}$levels were also tested in this study where rotenone (mitochondrial complex I), allopurinol (xanthine oxidase) and indomethacin (cyclooxygenase) diminished IMA relaxant responses while improving those of SV segments (Fig. 3D-F).

\section{Involvement of EDHF in Vasoreactivity}

The relevance of EDHF to vasoactivity was investigated by blocking all known pathways associated with vasoactivity using a cocktail of inhibitors i.e. L-NAME, ODQ, indomethacin and oxyhaemoglobin to scavenge $\mathrm{O}_{2}{ }^{-}$. These led to significant attenuations in endothelium-dependent dilatations and hence showed the inefficacy of EDHF in regulating these responses (Fig. 4).

\section{Involvement of cGMP in Vasoreactivity}

The cGMP inhibitor ODQ significantly suppressed endothelium-dependent relaxant responses in IMA 
A
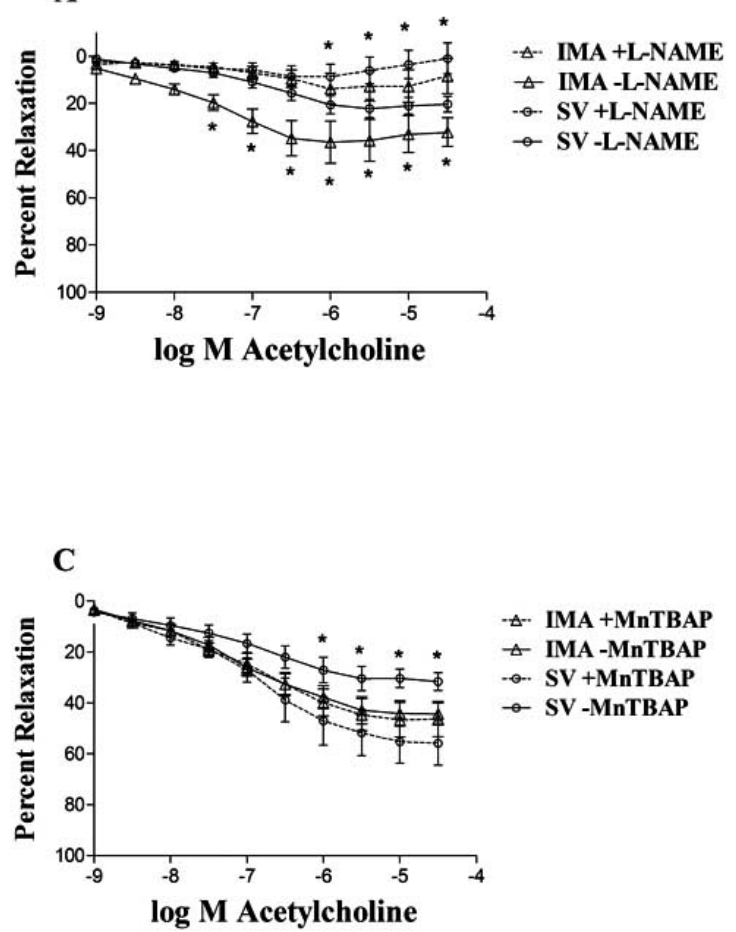

B
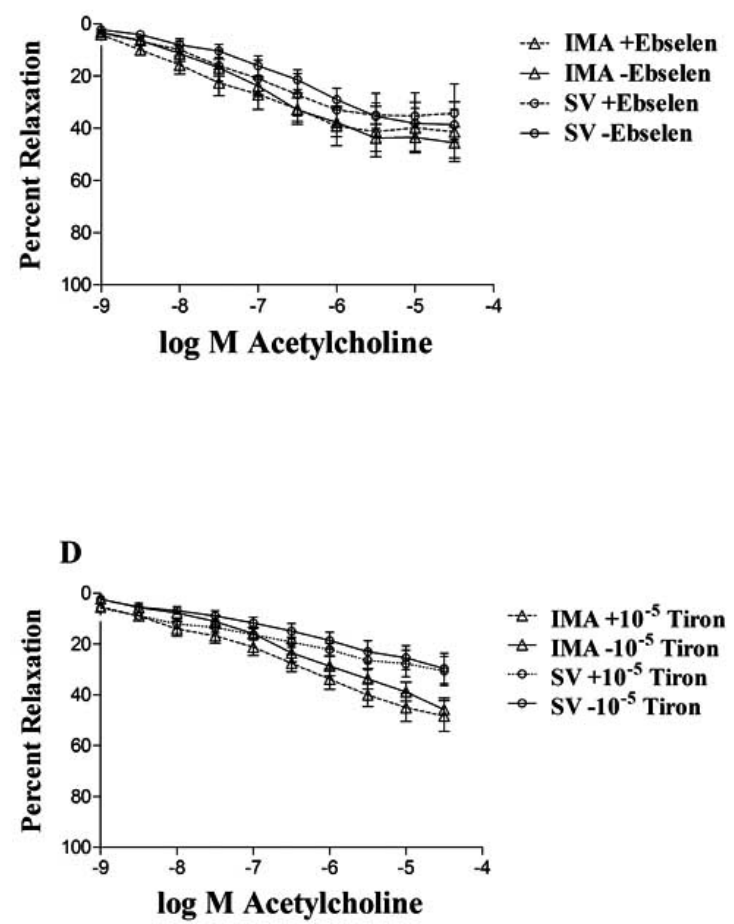

Fig. (2). Endothelium-dependent relaxant responses in IMA and SV in the absence and presence of L-NAME (A), ebselen (B) and MnTBAP (C) and $10^{-5} \mathrm{M}$ Tiron (D). Results are expressed as mean \pm SEM from 20 different patients. " $\mathrm{p}<0.05$ compared to controls.

regardless of its concentrations used in the experiments $\left(3 \times 10^{-6} \mathrm{M}\right.$ and $10^{-5} \mathrm{M}$ ) but failed to influence these responses in $\mathrm{SV}$ segments. In contrast, supplementation of $\mathrm{K}^{+}$solution with ODQ potentiated the contractile responses in IMA while reducing those in SV (Fig. 5A-D).

\section{DISCUSSION}

Arterial conduits are increasingly the preferred conduits for CABG. SV grafts demonstrate lower patency rates, a cause of ischaemic morbidity and mortality [1,2]. Injury exerted during surgical preparation and exposure to arterial haemodynamics are considered amongst the main factors that promote SV graft failure [12, 13]. However, neither better preoperative patient selection nor improved intraoperative handling of conduits has eradicated this discrepancy between SV and arterial grafts even at 10 years postoperatively $[1,14]$.

Histological studies have attributed prolonged patency of arterial over venous grafts to their relative immunity to atherosclerosis [15]. It is reasonable to suggest that inherent properties of the conduits may dictate their patency [16]. Although these properties remain largely unknown, altered endothelial function may be a contributing factor.

The endothelium plays a pivotal role in the regulation of vascular tone by releasing several vasoactive compounds [7]. Of these, NO contributes most to resting vascular tone and appears to be produced more in IMA than SV [17, 18]. The present study using endothelium-dependent relaxation as an index of NO production has shown greater relaxant responses in IMA than SV where an inhibitor of NOS (LNAME) radically suppressed these responses in both conduits. In contrast, experiments with $\mathrm{KCl}$ led to greater contractility in IMA than SV after indexing to the conduit size. Given the presence of a modest smooth muscle layer in $\mathrm{SV}$ compared to distal muscular part of IMA from which the samples were harvested, these findings were anticipated [19]. However, to ascertain if differences in vascular smooth muscle function may contribute endothelium-independent relaxations to SNP were investigated which led to complete relaxation of both conduits and confirmed the presence of intact functionally similar smooth muscle layers in both conduits. These data indicate the importance of endothelium in determining the overall vasoreactivity.

To explore the possibility that enhanced basal production of EDHF may contribute to augmented IMA relaxant responses, the cGMP, NO and cyclooxygenase pathways were concomitantly inhibited prior to detection of endothelium-dependent relaxant responses; these were significantly accentuated in both conduits thereby dismissing the possibility of EDHF being the main vasorelaxant in these vessels. This was in line with reports suggesting that EDHF must be a mechanism with several key players including vessel size, environment and local NO levels rather than a single molecule like $\mathrm{H}_{2} \mathrm{O}_{2}[20,21]$. In support of this, our studies with ebselen, a cell-permeable GPx mimetic that metabolizes $\mathrm{H}_{2} \mathrm{O}_{2}$, did not yield any changes in endotheliumderived relaxations in either conduit despite reducing vascular $\mathrm{H}_{2} \mathrm{O}_{2}$ levels at the concentration employed in the experiments [22].

Enhanced oxidative status, characterised by excessive presence of ROS, has recently been reported in SV [7, 23]. The relevance of $\mathrm{O}_{2}^{-{ }^{-}}$, the foundation molecule of all free radicals, to vasodilatations was tested in this study using 
$\mathbf{A}$

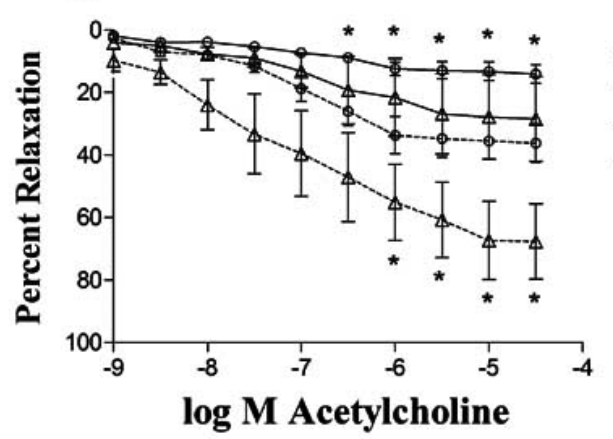

B

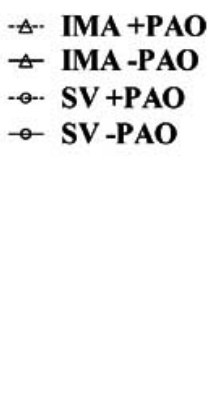

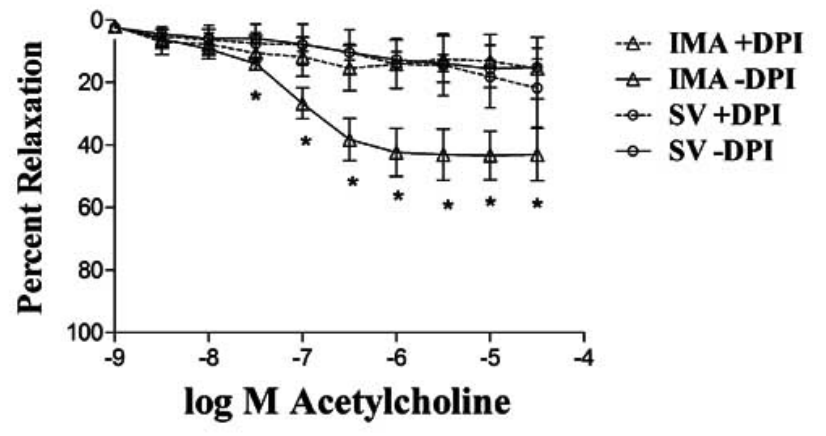

D

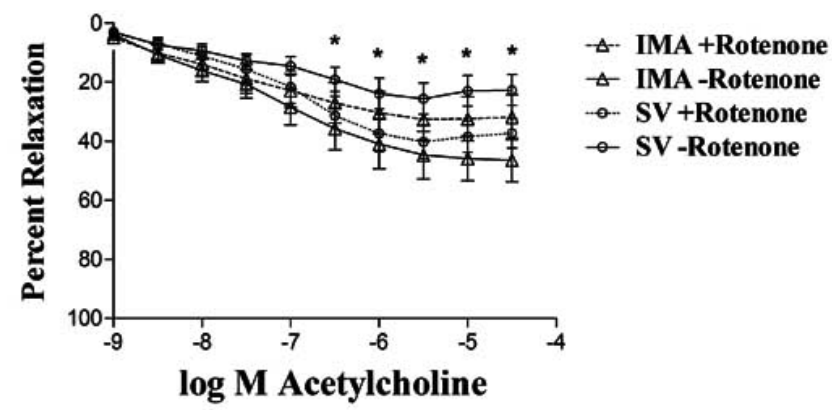

$\mathbf{F}$

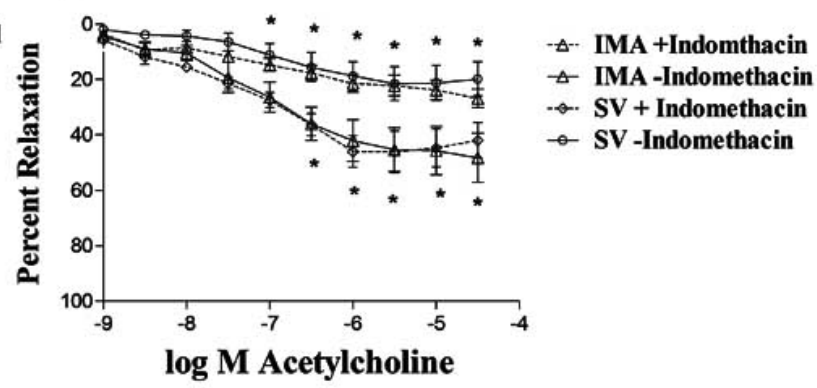

Fig. (3). Endothelium-dependent relaxant responses in IMA and SV in the absence and presence of PAO (A), DPI (B), AEBSF (C), rotenone (D), allopurinol (E) and indomethacin $(\mathbf{F})$. Results are expressed as mean \pm SEM from 14 different patients. * $\mathrm{p}<0.05$ compared to controls.

both a $\mathrm{O}_{2}{ }^{--}$scavenger (Tiron) and the selective inhibitors of pro-oxidant enzyme NADPH oxidase where Tiron and PAO improved relaxant responses in both conduits while AEBSF and DPI exerted vessel-specific effects (suppressed relaxant responses in IMA without affecting those of SV). As our experiments were performed in a blood-free environment, it is unlikely that inflammatory sources are involved in $\mathrm{O}_{2}{ }^{-}$ production. Hence, the findings imply that PAO, a wellknown inhibitor of the phagocyte oxidase, can also affect other isoform(s) such as that shown to exist in layers of the arterial wall and that secondary enzyme systems such as flavoproteins and serine proteases (inhibited by DPI and AEBSF, respectively) are equally important in maintaining arterial tone [24]. In this context, the specific contributions of other $\mathrm{O}_{2}^{-{ }^{-}}$-generating enzymes, (xanthine oxidase, cyclooxygenase and mitochondrial complex I) to vasorelaxation were also assessed through use of their specific inhibitors which augmented relaxant responses in 


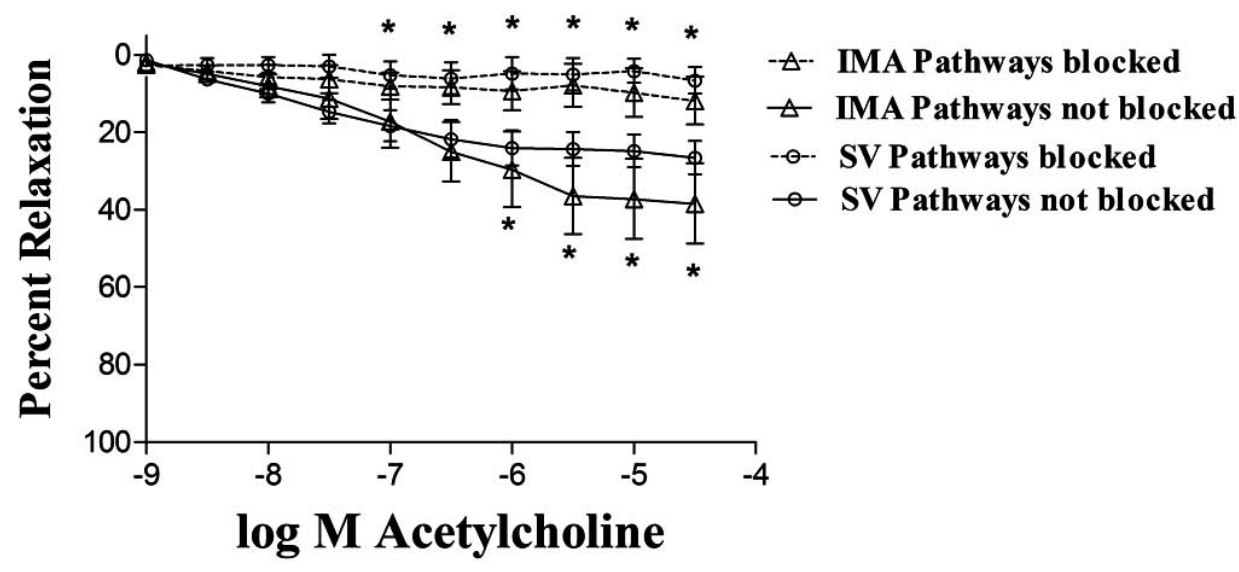

Fig. (4). Endothelium-dependent relaxant responses in IMA and SV in the absence and presence of blockade of all known relaxant pathways to assess the contribution of EDHF. Results are expressed as mean \pm SEM from 17 patients. ${ }^{*} \mathrm{p}<0.05$ compared to controls.
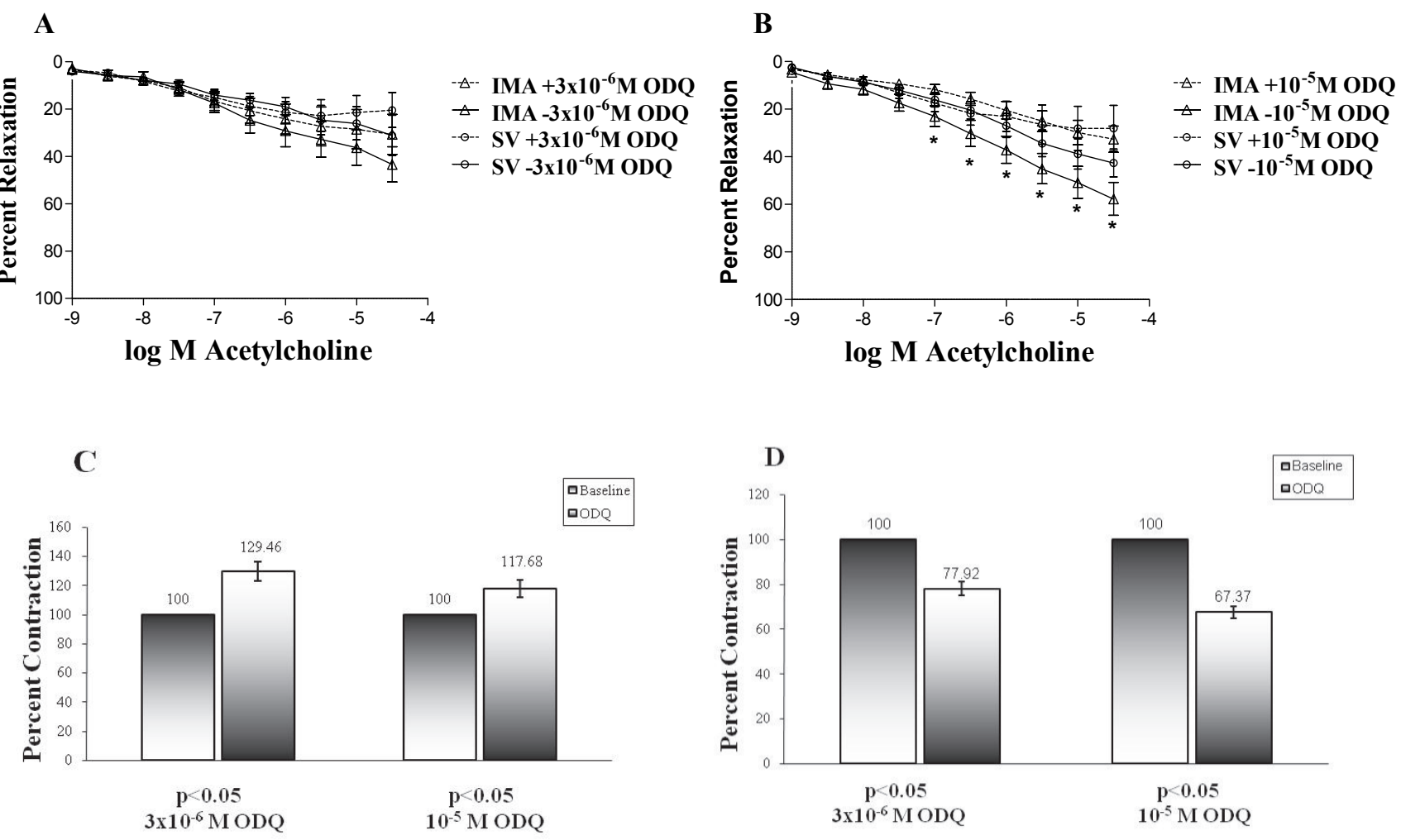

Fig. (5). Endothelium-dependent relaxant (A-B) and contractile (C-D) responses in IMA and SV in the absence and presence of $3 \times 10^{-6} \mathrm{M}$ or $10^{-5} \mathrm{M}$ ODQ, respectively. Relaxant results are expressed as mean \pm SEM from 19 different patients. ${ }^{*} \mathrm{p}<0.05$ compared to controls.

the SV while worsening IMA dilatation. These findings indicate that oxidative stress is generated and possibly tackled by a variety of enzymes in arterial and venous conduits in a different manner. Indeed, the data comparing SOD activity and $\mathrm{O}_{2}{ }^{--}$availability in $\mathrm{SV}$ to those in IMA have been rather contradictory [10, 23]. Our experiments designed to elevate the vascular levels of SOD through a cell-permeable SOD mimetic (MnTBAP) led to improved endothelial function in both conduits, albeit significantly only in the SV. In addition to catabolising $\mathrm{O}_{2}{ }^{--}$, MnTBAP also scavenges $\mathrm{OONO}^{-}$, which is able to diminish eNOS activity by reducing the bioavailability of its cofactor tetrahydrobiopterin. Collectively, these findings suggest that the poor long-term patency of SV may be due to diminished SOD activity and/or exaggerated availability of $\mathrm{O}_{2}{ }^{--}$.

Once synthesised in the vascular endothelium, NO promotes smooth muscle cell relaxation by binding to the haem moiety of soluble guanylate cyclase and increasing the production of cGMP [25]. Given the existence of different levels $\mathrm{O}_{2}^{--}$in $\mathrm{SV}$ versus IMA and the ability of $\mathrm{O}_{2}{ }^{--}$to inhibit cGMP-dependent relaxation in bovine pulmonary arteries [26], the correlation of this pathway to IMA and SV relaxations was investigated for the first time in this study using a soluble guanylyl cyclase inhibitor (ODQ) which 
dramatically reduced these responses in IMA in a dosedependent fashion. Although similar decreases were also observed in SV relaxations, these did not attain statistical significance. Furthermore, blockage of this pathway resulted in enhanced contractile responses in the IMA and reduced those of SV thereby adding further support for the greater involvement of this mechanism in IMA vasoactivity.

Within each group, there has been an even distribution of each risk-factor to negate any confounding effect. Moreover, each conduit acted as its own internal control, allowing for the specific action of each study chemical on reactivity responses to be isolated.

\section{Limitations of the Study}

This study has focused on the functional responses of vascular conduits without looking into mRNA/protein expressions or enzyme activities of the appropriate prooxidant and antioxidant enzymes. In situations where an unexpected vasoreactivity is produced, there may well be a simple explanation were these data available. It most be noted that more than one ROS may be affected by the study chenmicals; for instance MnTBAP can affect peroxynitrite levels as well as $\mathrm{O}_{2}{ }^{--}$. This investigation has been conducted using two bypass conduits and did not include the responses of radial arteries due to inadequate numbers of available patient samples. Similarly, the numbers and the sizes of the patients' samples prevented us from determining the levels of $\mathrm{O}_{2}{ }^{-}$and $\mathrm{OONO}^{-}$before and during treatments with different agents.

\section{ACKNOWLEDGEMENTS}

This investigation was supported by a HPSS training Fellowship (A.D.M) provided by the Research and Development Office, Northern Ireland, reference EAT/2204/02. ADM performed all of the experiments and data analysis. All authors were involved in the manuscript drafting and revision process. We are very grateful to the cardiac surgical teams, Royal Victoria Hospital, Belfast for their assistance with the provision of tissue samples.

\section{ABBREVIATIONS}

$\begin{array}{ll}\mathrm{CABG} & =\text { Coronary artery bypass grafting } \\ \mathrm{IMA} & =\text { Internal mammary artery } \\ \mathrm{O}_{2}^{--} & =\text {Superoxide } \\ \mathrm{NO} & =\text { Nitric oxide } \\ \mathrm{ROS} & =\text { Reactive oxygen species } \\ \mathrm{SV} & =\text { Saphenous vein }\end{array}$

\section{REFERENCES}

[1] Loop, F.D.; Lytle, B.W.; Cosgrove, D.M.; Stewart, R.W.; Goormastic, M.; Williams, G.W.; Golding, L.A.; Gill, C.C.; Taylor, P.C.; Sheldon, W.C.; Proudfit, W.L. Influence of the internalmammary-artery graft on 10-year survival and other cardiac events. N. Engl. J. Med., 1986, 314, 1-6.

[2] Endo, M.; Tomizawa, Y.; Nishida, H. Bilateral versus unilateral internal mammary revascularisation in patients with diabetes. Circulation, 2002, 108, 1343-1349.

[3] Hamilton, C.A.; Berg, G.; McIntyre, M.; McPhaden, A.R.; Reid, J.L.; Dominiczak, A.F. Effects of nitric oxide and superoxide on relaxation in human artery and vein. Atherosclerosis, 1997, 133, 77-86.
[4] Cable, D.G.; Caccitolo, J.A.; Pfeifer, E.A.; Daly, R.C.; Dearani, J.A.; Mullany, C.J.; O'Brien, T.; Orszulak, T.A.; Schaff, H.V. Endothelial regulation of vascular contraction in radial and internal mammary arteries. Ann. Thorac. Surg., 1999, 67, 1083-1090.

[5] Hamilton, C.A.; Brosnan, M.J.; Al-Benna, S.; Berg, G.; Dominiczak, A.F. NAD(P)H oxidase inhibition improves endothelial function in rat and human blood vessels. Hypertension, 2002, 40, 755-762.

[6] Yang, Z.W.; Zheng, T.; Zhang, A.; Altura, B.T.; Altura, B.M. Mechanisms of hydrogen peroxide-induced contraction of rat aorta. Eur. J. Pharmacol., 1998, 344, 169-181.

[7] Bayraktutan, U. Free radicals, diabetes and endothelial dysfunction. Diabet. Obes. Metabol., 2002, 4, 224-238.

[8] Xia, Y.; Dawson, V.L.; Dawson, T.M.; Snyder, S.H.; Zweier, J.L. Nitric oxide synthase generates superoxide and NO in argininedepleted cells leading to peroyxnitrite-mediated cellular injury. Proc. Natl. Acad. Sci. USA., 1996, 93, 6770-6774.

[9] Sakari, T.; Sugioka, K.; Nakano, M. $\mathrm{O}_{2}^{-}$generation and lipid peroxidation during oxidation of glycated polypeptide, glycated polylysine, in the presence of iron-ADP. Biochem. Biophys. Acta., 1997, 1043, 27-33.

[10] Berry, B.; Hamilton, C.A.; Brosnan, J.; Magill, F.G.; Berg,. G.A.; McMurray, J.J.; Dominiczak, A.F. Investigation into the sources of superoxide in human blood vessels: angiotensin II increases superoxide production in human internal mammary arteries. Circulation, 2000, 101, 2206-2212.

[11] Yu, B.P. Cellular defences against damage from reactive oxygen species. Physiol. Rev., 1994, 74, 139-162.

[12] Domanski, M.J.; Borkowf, C.B.; Campeau, L.; Knatterud, G.L.; White, C.; Hoogwerf, B.; Rosenberg, Y.; Geller, N.L. Prognostic factors for atherosclerosis progression in saphenous vein grafts. The postcoronary artery bypass graft (Post-CABG) trial. J. Am. Coll. Cardiol., 2000, 36, 1877-1883.

[13] Shuhaiber, J.H.; Evans, A.N.; Massad, M.G.; Geha, A.S. Mechanisms and future directions for prevention of vein graft failure in coronary bypass surgery. Eur. J. Cardiothorac. Surg., 2002, 22, 387-396.

[14] Grondin, C.M.; Campeau, L.; Enjalbert, M.; Bourassa, M.G. Comparison of late changes in internal mammary artery and saphenous vein grafts in two consecutive series of patients 10 years after operation. Circulation, 1984, 70, I208-I212.

[15] Sims, F.H. A comparison of coronary and internal mammary arteries and implications of the results in the etiology af arteriosclerosis. Am. Heart. J., 1983, 105, 560-566.

[16] Lytle, B.W.; Cosgrove, D.M.; Ratliff, N.B.; Easley, K.; Taylor, P.C. Long-term (5-12 years) serial studies of internal mammary artery and saphenous vein coronary bypass grafts. J. Thorac. Cardiovasc. Surg., 1985, 89, 248-258.

[17] Luscher, T.F.; Diederich, D.; Siebenmann, R.; Lehmann, K.; Stultz, P.; von Segesser, L.; Yang, Z.H.; Turina, M.; Gradel, E.; Weber, E.; and et al. Difference between endothelium-dependent relaxation in arterial and in venous coronary bypass grafts. N. Engl. J. Med., 1988, 319, 462-467.

[18] Davies, M.G.; Hagen, P.-O. Pathophysiology of vein graft failure. Eur. J. Vasc. Endovasc. Surg., 1995, 9, 7-18.

[19] Canham, P.B.; Finlay, H.M.; Boughner, D.R. Contrasting structure of the SV and IMA used as coronary bypass vessels. Cardiovasc. Res., 1997, 34, 557-567.

[20] Luksha, L.; Agewall, S.; Kublickiene, K. Endothelium-derived hyperpolarizing factor in vascular Physiology and cardiovascular disease. Atherosclerosis, 2008, 202, 330-344.

[21] Miura, H.; Bosnjak, J.J.; Ning, G.; Saito, T.; Miiura, M.; Gutterman, D.D. Role for hydrogen peroxide in flow-induced dilation of human coronary arterioles. Circ. Res., 2003, 92, e31e40.

[22] Ghatta, S.; Hemmer, R.B.; Uppala, S.; O'Rourke, S.T. Role of endogenous hydrogen peroxide in the development of nitrate tolerance. Vasc. Pharmacol., 2007, 46, 247-252.

[23] Shi, Y.; Patel, S.; Davenpeck, K.L.; Niculescu, R.; Rodriguez, E.; Magno, M.G.; Ormont, M.L.; Mannion, J.D.; Zalewski, A. Oxidative stress and lipid retention in vascular grafts. Circulation, 2001, 103, 2408- 2413.

[24] Babior, B.M. NADPH oxidase: an update. Blood, 1999, 93, 14641476. 
[25] Rapoport, R.M.; Murad, F. Agonist-induced endotheliumdependent relaxation in rat thoracic aorta may be mediated through cGMP. Circ. Res., 1983, 52, 352-357.
[26] Cherry, P.D.; Omar, H.A.; Stuart, J.S.; Wolin, M.S. Superoxide anion inhibits cGMP-associated bovine pulmonary arterial relaxation. Am. J. Physiol., 1990, 259, H1056-H1062.

(C) Muir et al.; Licensee Bentham Open.

This is an open access article licensed under the terms of the Creative Commons Attribution Non-Commercial License (http://creativecommons.org/licenses/by-nc/3.0/) which permits unrestricted, non-commercial use, distribution and reproduction in any medium, provided the work is properly cited. 